\section{EPV184/\#232 AN OVERVIEW OF GYNECOLOGICAL ONCOLOGY CLINICAL QUALITY REGISTRIES WORLDWIDE}

${ }^{1} \mathrm{~N}$ Baldewpersad Tewarie*, ${ }^{2} \mathrm{M}$ Wouters, ${ }^{3} \mathrm{~W}$ Van Driel, ${ }^{1} \mathrm{M}$ Van Ham, ${ }^{4} \mathrm{R}$ Rome, ${ }^{5} \mathrm{E}$ Pagano, ${ }^{6} \mathrm{C}$ Høgdall, ${ }^{7} \mathrm{~T}$ Hogberg, ${ }^{8} \mathrm{R}$ Kruitwagen. ${ }^{1}$ Radboud UMC, Gynecology, Nijmegen, Netherlands; ${ }^{2}$ Netherlands Cancer Insitute, Surgical Oncology, Amsterdam, Netherlands; ${ }^{3}$ Netherlands Cancer Insitute, Gynecology, Amsterdam, Netherlands; ${ }^{4}$ Epworth Healthcare, Epworth Freemasons Hospital, East Melbourne, Australia; ${ }^{5}$ Citta della Salute, Clinical Epidemiology Unit, Pienmonte, Italy; ${ }^{6}$ University of Copenhagen, Gynecology, Copenagen, Denmark; ' Lund university, Medical Oncology, Lund, Sweden; ${ }^{8}$ Maastricht University Medical Centre, Gynecology, Maastricht, Netherlands

\subsection{6/ijgc-2021-IGCS.255}

Objectives Clinical outcomes have become more important over the past years, Clinical Quality Registries (CQR's) were initiated in order to compare clinical outcomes between hospitals or regions within a country. The aim of this study was to identify CQR's for gynecological oncology and to summarize their characteristics, processes, and quality indicators (QI) in order to establish whether it is feasible to make an international comparison in the future.

Methods To identify CQR's in gynecological oncology a literature search in Pubmed was performed. All papers describing the use of a CQR were selected and analyzed. For the purpose of this paper, the task force or contact person of these registries were approached to participate in order to collect information on registered items, processes, and indicators.

Results Five nations with CQR's agreed to collaborate: Australia, Denmark, Italy, the Netherlands and Sweden. Denmark, the Netherlands and Sweden established a nationwide registry, collecting data on multiple tumor types, and reporting various QI's. Australia and Italy registered and reported on patients with ovarian cancer only. All nations had a different process to report the results to the participating hospitals.

Conclusions This review of CQR's on gynecological malignancies shows that different methods and processes exist. Registries serve the same purpose to improve quality of care but vary in reporting for one or more tumor types. In order to compare the care for these patients on an international level, it would be useful to harmonize these registries, set an international standard to measure the quality of care, and select similar indicators.

\section{EPV185/\#234 EVOLVING OVARIAN CANCER TREATMENT PATTERNS IN THE UNITED STATES FROM 1982- 2018: RESULTS FROM THE TEMPUS DATASET}

${ }^{1} \mathrm{E}$ Szamreta*, ${ }^{1} \mathrm{M}$ Monberg, ${ }^{1} \mathrm{Y} \mathrm{Li}^{2}{ }^{2} \mathrm{M}$ Othus. ${ }^{1}$ Merck and Co., Inc., Center for Observational and Real-world Evidence (CORE), Kenilworth, USA; ${ }^{2}$ Fred Hutchinson Cancer Research Center, Biostatistics and Biomathematics, Seattle, USA

\subsection{6/ijgc-2021-IGCS.256}

Objectives Surgery and platinum-taxane doublet (PTD) chemotherapy are standard treatment for ovarian cancer (OC); adoption of maintenance therapies has been more limited. This analysis describes characteristics of OC patients and real-world treatment patterns.

Methods The Tempus dataset contains EMR data on U.S. oncology patients. This study included women with a primary diagnosis of OC; women treated with poly-ADP ribose polymerase inhibitors (PARPi), pembrolizumab, or nivolumab were excluded $(n=288$; final $n=3,370)$. Descriptive statistics were
Abstract EPV185/\#234 Table 1

\begin{tabular}{|c|c|c|c|c|}
\hline & Overall & $\begin{array}{c}\text { Diagnosed } \\
1982-2005\end{array}$ & $\begin{array}{c}\text { Diagnosed } \\
\mathbf{2 0 0 6}-2012\end{array}$ & $\begin{array}{c}\text { Diagnosed } \\
2013-2018\end{array}$ \\
\hline Have Received: & $\mathrm{n}=3,370$ & $\mathrm{n}=998$ & $\mathrm{n}=1,660$ & $\mathrm{n}=548$ \\
\hline Surgery & $3,050(90.5 \%)$ & $929(93.1 \%)$ & $1,520(91.6 \%)$ & $474(86.5 \%)$ \\
\hline Hysterectomy & $2,128(63.1 \%)$ & $646(64.7 \%)$ & $1,086(65.4 \%)$ & $332(60.6 \%)$ \\
\hline Omentectomy & $2,247(66.7 \%)$ & $650(65.1 \%)$ & $1,162(70.0 \%)$ & $348(63.5 \%)$ \\
\hline Other debulking surgery & $2,692(79.9 \%)$ & $791(79.2 \%)$ & $1,378(83.0 \%)$ & $435(79.4 \%)$ \\
\hline Lymph node dissection & $2,259(67.0 \%)$ & $633(63.4 \%)$ & $1,186(71.4 \%)$ & $377(68.8 \%)$ \\
\hline Bowel resection & $665(19.7 \%)$ & $210(21.0 \%)$ & $355(21.4 \%)$ & $81(14.8 \%)$ \\
\hline Radiotherapy & $434(12.9 \%)$ & $186(18.6 \%)$ & $187(11.3 \%)$ & $40(7.3 \%)$ \\
\hline Neither & $291(8.6 \%)$ & $60(6.0 \%)$ & $127(7.7 \%)$ & $70(12.8 \%)$ \\
\hline & & & & \\
\hline Received platinum & $\mathrm{n}=2,041$ & $\mathrm{n}=426$ & $\mathrm{n}=1,115$ & $\mathrm{n}=440$ \\
\hline Platinum+taxane doublet regimen & $1,966(96.3 \%)$ & $393(92.3 \%)$ & $1,092(97.9 \%)$ & $429(97.5 \%)$ \\
\hline Combo regimen containing bev & $161(7.9 \%)$ & $303(71.1 \%)$ & $808(72.5 \%)$ & $307(69.8 \%)$ \\
\hline Other combo regimen & $114(5.6 \%)$ & $35(8.0 \%)$ & $93(8.3 \%)$ & $37(8.4 \%)$ \\
\hline \multicolumn{1}{|c|}{$\mathrm{n}$} & $\mathrm{n}=1,763$ & $\mathrm{n}=458$ & $\mathrm{n}(4.4 \%)$ & $25(5.7 \%)$ \\
\hline Received platinum & $852(48.3 \%)$ & $258(56.3 \%)$ & $435(47.5 \%)$ & $125(39.4 \%)$ \\
\hline Platinum+taxane doublet regimen & $243(13.8 \%)$ & $106(23.1 \%)$ & $98(10.7 \%)$ & $29(9.1 \%)$ \\
\hline Combo regimen containing bev & $357(20.2 \%)$ & $45(9.8 \%)$ & $178(19.5 \%)$ & $110(34.7 \%)$ \\
\hline Other combo regimen & $732(41.5 \%)$ & $220(48.0 \%)$ & $399(43.6 \%)$ & $93(29.3 \%)$ \\
\hline
\end{tabular}

calculated for patient characteristics, surgery/radiation/chemotherapy, and time from diagnosis to surgery.

Results Median age at diagnosis was $60,55 \%$ of patients were advanced-stage and 36\% were ECOG 0/1. 91\% had surgery, $13 \%$ radiation, and 9\% neither. Median time from diagnosis was approximately 7.5 months for most surgeries, but longer for omentectomy (16 months) and bowel resection (10 months). of patients receiving first-line (1L) chemotherapy $(n=2,041), 96 \%$ received a platinum (71\% PTD), 7\% received bevacizumab (bev) + PTD, and $3 \%$ received bev maintenance. In second-line (2L), 48\% received a platinum, 14\% PTD, 6\% PTD + bev, 6\% bev maintenance, and 39\% single-agent therapy. Patterns over time are shown in the table 1.

Conclusions Most OC patients received surgery and 2/3 received chemotherapy. PTD was the predominant $1 \mathrm{~L}$ regimen, and in $2 \mathrm{~L}$ platinum was used in nearly half of patients. Bev was the most used maintenance therapy for $2 \mathrm{~L}$, and use increased over time. Understanding these historical patterns helps inform stakeholders of the opportunity for PARPi and other advances in OC treatment.

\section{EPV186/\#240 KNOWLEDGE ABOUT ADVANCED OVARIAN CANCER AND MAINTENANCE THERAPY: DOES EXPERIENCE MATTER?}

${ }^{1} \mathrm{M}$ Basabe ${ }^{*},{ }^{1} \mathrm{C}$ Sun, ${ }^{2} \mathrm{R}$ Volk, ${ }^{2} \mathrm{~L}$ Lowenstein, ${ }^{1} \mathrm{~A}$ Schneider, ${ }^{2} \mathrm{~V}$ Leal, ${ }^{2} \mathrm{~L}$ Covarrubias Crocker, ${ }^{2} \mathrm{~J}$ Alexander, ${ }^{1} \mathrm{M}$ Iniesta, ${ }^{1} \mathrm{~L}$ Meyer. ${ }^{1}$ The University of Texas MD anderson Cancer Center, Gynecologic Oncology and Reproductive Medicine, Houston, USA; ${ }^{2}$ The University of Texas MD Anderson Cancer Center, Health Services Research, Houston, USA

\subsection{6/ijgc-2021-IGCS.257}

Objectives As part of a study to construct a shared-medical decision tool for ovarian cancer maintenance therapy (MT), we developed a knowledge survey to measure patients' understanding of their cancer and treatment. With the recent expansion of MT indications, patients need to decide if MT is right for them. An understanding of potential risks and benefits associated with MT is paramount to making an informed decision. We explored knowledge differences between newly diagnosed and recurrent patients.

Methods A 32-question survey focused on ovarian cancer (OC) and MT was developed based on interviews with patients and subject matter experts. The survey was modified 